\title{
Label-free NIR-SERS discrimination and detection of foodborne bacteria by in situ synthesis of Ag colloids
}

\author{
Longyan Chen, Nawfal Mungroo, Luciana Daikuara and Suresh Neethirajan *
}

\begin{abstract}
Background: Rapid detection and discrimination of bacteria for biomedical and food safety applications remain a considerable challenge. We report a label-free near infrared surface-enhanced Raman scattering (NIR-SERS) method for the discrimination of pathogenic bacteria from drinking water. The approach relies on the in situ synthesis of silver nanoparticles (Ag NPs) within the bacterial cell suspensions.

Results: Pre-treatment of cells with Triton X-100 significantly improved the sensitivity of the assay. Using this method, we were able to discriminate several common pathogenic bacteria such as Escherichia coli, Pseudomonas aeruginosa, Methicillin-resistant Staphylococcus aureus (MRSA) and Listeria spp. A comparison of the SERS spectra allowed for the discrimination of two Listeria species, namely L. monocytogenes and L. innocua. We further report the application of the method to discriminate two MRSA strains from clinical isolates. The complete assay was completed in a span of 5 min

Conclusions: The proposed analytical method proves to be a rapid tool for selective and label-free identification of pathogenic bacterium. Pre-treatment of bacterial cells with Triton X-100 resulted in new features on the SERS spectra, allowing for a successful discrimination of common disease related bacteria including E. coli, P. aeruginosa, Listeria and MRSA. We also demonstrate that the spectral features obtained using in situ synthesis of nanoparticles could be could be used to differentiate two species of listeria. By using L. innocua as a model sample, we found the limit of detection of our assay to be $10^{3} \mathrm{CFU} / \mathrm{mL}$. The method can selectively discriminate different bacterial species, and has a potential to be used in the development of point-of-care diagnostics with biomedical and food safety applications.
\end{abstract}

Keywords: Surface-enhanced Raman scattering, Silver nanoparticles, Bacteria, Discrimination, In situ synthesis

\section{Background}

Rapid detection and differentiation of pathogenic bacteria have become an increasingly important task in the pharmaceutical sector, medical and veterinary diagnostics, water and food safety, and food-processing industries. Conventional pathogen identification methods based on biochemical and microbiological tests requires a pure isolated bacterial culture and expensive equipment, which is laborious and time-consuming $[1,2]$. Meanwhile the over usage of antibiotics in the clinical treatment of bacterial infections results in the emergence

*Correspondence: sneethir@uoguelph.ca

BioNano Laboratory, School of Engineering, University of Guelph, Guelph, ON N1G 2W1 12, Canada of "super bugs" bacterial species with undesirable antimicrobial resistance [3], which put additional cost to the public health budget. Advanced methods like polymerase chain reaction (PCR) and immunological detection generate results quicker than culture-based methods $[4,5]$. However, they are often limited in regards to accuracy, specificity, speed, cost efficiency, versatility and sensitivity [6]. There is an urgent demand for a method that can deliver fast detection of pathogenic bacteria without the necessity of enrichment or culturing steps, and a detection limit in the $1-100 \mathrm{CFU}$ per $\mathrm{ml}$ range $[7,8]$ leads to alternative approaches for rapid discrimination of pathogen. 
Raman spectroscopy is becoming attractive for analysis of chemical and biological components [9, 10], even in a label-free modes. Raman spectroscopy has potential to detect a broad range of biological and chemical substances [11], and reveal the molecular composition of a sample at micrometer scale [12]. Raman signal of molecules can be dramatically enhanced by metallic nanoparticles (NPs) on the order of $10^{4}-10^{6}$ using surface-enhanced Raman spectroscopy (SERS) via Surface Plasmon Resonance (SPR) [5, 13].

Surface-enhanced Raman spectroscopy techniques have been tested extensively for the detection, imaging, and discrimination of bacteria [11, 14-18]. Spectral signatures have been demonstrated to accurately distinguish gram-negative and gram-positive bacteria as the scattering intensity of gram positive bacteria has generally been observed to be higher than that of the gram negative bacteria across a range of wavelengths [19]. There are several approaches that have been employed for the detection of bacteria using SERS. Zhang and colleagues have reported the synthesis of magnetic-plasmonic $\mathrm{Fe}_{3} \mathrm{O}_{4}-\mathrm{Au}$ core-shell nanoparticles to concentrate bacterial cells by applying an external point magnetic field, as well as detection and identification of different bacteria using SERS [20]. More recently, Zhou et al. have reported a bio-sensing method for the detection of live bacteria in drinking water by coating with Ag nanoparticles [21] as well as detection of anthrax spores on nanosphere substrates [22]. A novel application employing SERS-active substrate composed of an array of Ag-nanoparticles imbedded in anodic aluminum oxide with nanochannels has been shown to exhibit a highly reproducible Raman signal enhancement factor due to the uniform narrow gaps between Ag-nanoparticles [23]. More complex nanohybrid systems developed by combining antibodyconjugated gold nanoparticles with single-walled carbon nanotubes have been used to detect multi drug resistant Salmonella spp. [24].

The predominant approach for the identification of bacteria by SERS is mixing as-made gold (Au NPs) and silver nanoparticles (Ag NPs) of various shapes or aggregates with bacterial cell suspension, as it is a label free method requiring minimal or no preparatory steps. Yet, it is very difficult to probe the fingerprints for various bacteria due to poor spectral reproducibility and selectivity through simple mixing process. Alternative method was directly producing NPs (in situ) in the bacterial cell suspension (through external-cell wall or internal-interior components modes), as reported by Efrima's group [11, 18, 25]. This in situ approach ensures homogenous contact of constituents of the bacterial cells to NPs and hence gives an intense spectrum with unusual reproducibility and a better selectivity. However, the spectra obtained through an external mode are very similar among various bacterial species, which makes this mode unsuitable for bacterial discrimination from polymicrobial samples. Spectral similarities are attributed to flavin adenine dinucleotides (FAD), an important coenzyme known to be commonly present in the inner side of the bacterial cell wall [25]. Alternatively, the internal mode shows a distinct spectra with the absence of flavin spectral signature which is relatively weak due to a lesser degree of NPs aggregation [11]. Extraction of bacterial plasma from cell wall could possibly enhance the signal for the detection and discrimination. However, the treatment is rather time-consuming and not suitable for low concentration of bacterial cells. Smith-Palmer et al. [26] report that the SERS signal from FAD could be greatly reduced by excitation at near infrared (NIR) light source $(785 \mathrm{~nm})$ rather than the excitation at $514 / 532 \mathrm{~nm}$, as reported by Efrima's group [26]. The advantages of using NIR light source are that it allows for non-invasive probing of biological processes and discrimination of pathogenic bacteria in a low fluorescence background.

In this study, we report a label free NIR-SERS assay for discrimination and detection of bacteria in drinking water through in situ preparation of Ag NPs. We found that the selectivity of bacteria for discrimination could be enhanced greatly by the addition of cell membrane disruption reagent Triton X-100. By using the proposed method, we were able to discriminate two species of bacteria i.e., Listeria and within subtypes of bacterium such as Methicillin-resistant Staphylococcus aureus (MRSA) from clinical samples.

\section{Results and discussion}

\section{NIR-SERS characterization of bacteria through in situ} method

Bacterium Escherichia coli was first used to demonstrate the applicability of NIR-SERS in situ assay. As shown in Figure 1, we could find distinguishable and sharp peaks from spectrum obtained by external mode (Figure 1c). In contrast, only a few weak bands $\left(890\right.$ and $1,040 \mathrm{~cm}^{-1}$ ) were observed from the spectrum taken by internal mode (Figure 1d). In addition, the Raman spectrum for pure AgNPs did not show any identical bands (Figure 1e). Raman spectrum for bacterial samples without NPs shows a broad band around $1,100 \mathrm{~cm}^{-1}$ and another identical peak around $457 \mathrm{~cm}^{-1}$ (Figure 1d). This spectrum is not like those as reported elsewhere [27], where distinct bands could be found for $E$. coli. The lack of distinct spectral band for this measurement was attributed to the relatively low sensitivity of the Raman spectrometer. When the E. coli cells were incubated with Triton X-100, we observed a sharp increase in the peak intensities as well as the number of peaks in the spectrum (Figure 1a). 


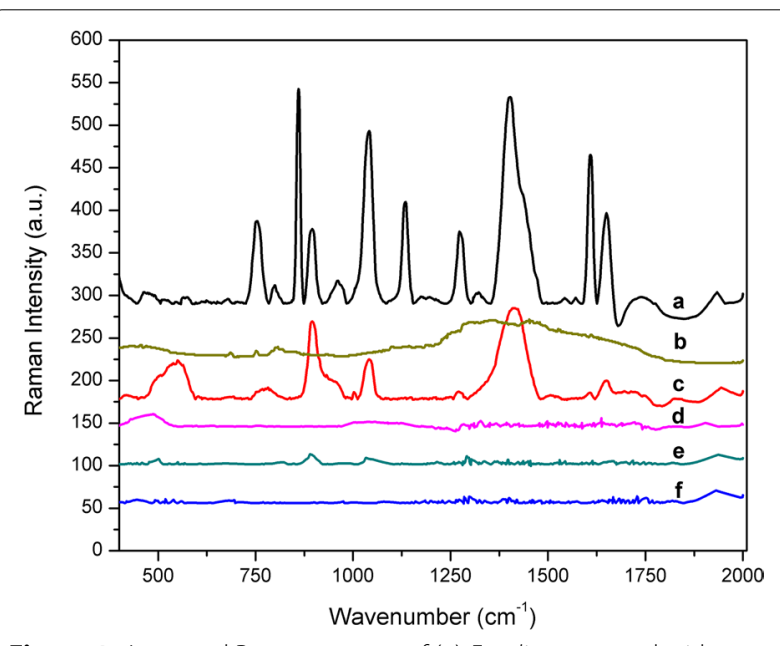

Figure 1 Averaged Raman spectra of (a) E. coli pre-treated with Triton X-100, (b) Triton X-100 only (with Ag NPs), (c) E. coli in external mode, (d) E. coli in internal mode, (e) Ag NPs only (without E. coli and Triton X-100) and (f) E. coli cells without Ag NPs.

Figure 1b shows the Raman spectrum of Triton X-100 in the presence of Ag NPs. No typical peaks were observed.

Fraction of bacterial cytoplasm could exhibit distinct Raman information for different bacterial cells [11]. However, as discussed above, the internal mode that collects the cytoplasmic information produces relatively lower intensity signal. On the other hand, it has been reported that Raman signals of biochemical information from cell interior could also be observed, by pre-treatment of cells with cell wall (or membrane) disrupting reagents such as antibiotics [23], ascorbic acid and Triton X-100 [25]. Triton X-100 is a detergent that can disrupt the integrity of the cell membranes, where the major components are lipids [28]. This results in exposure of inner components (such as proteins) from bacterial cells. Recently Reza Jalalirad [29] and Ma et al. [30] have shown selective permeabilization of proteins using Triton-X alone, without the presence of lysozyme.

We further examined the Raman spectra for $E$. coli by adding Triton X-100 (at a final concentration of $0.1 \%$ ). We estimated that there might be some components released from cytoplasm due to the changes in the permeability of cell membrane. The result in Figure 1a shows the presence of several strong peaks when the bacterial cells were treated with Triton X-100. These new shifts include $753,858,1,134,1,268,1,608$ and $1,656 \mathrm{~cm}^{-1}$. The tentative assignments of these shifts are listed in Additional file 1: Table S1, based on previous studies [16, 26, 31-33] (Additional file). Previous studies have reported that addition of Triton X-100 in human cells could increase the protein peaks in Raman spectra [34]. In our study, we observed the presence of new shifts namely,
$753,1,608$ and $1,656 \mathrm{~cm}^{-1}$, which reflects the vibrations of tryptophan, tyrosine and amide I from the bacterial proteins, respectively. Other than Triton X-100, Tween 20, Brij 58, Lubrol WX, Brij 98, Brij 96 [35], chitosan [36] and thymol [37] could also be possibly used to improve the sensitivity of the assay.

\section{Characterization}

The as-made Ag NPs without E. coli appear as a yellow/ greenish suspension. However in the presence of bacterial cells, the Ag NPs appear dark green in color. UV-vis spectrum indicates that there are two peaks at 358 and $400 \mathrm{~nm}$ for the Ag NPs made in the presence of bacterial cells (Figure 2a). The average diameter of Ag NPs measured by DLS is calculated to be $40 \pm 8.4 \mathrm{~nm}$ (Figure 2a upright). Those two absorption peaks could correspond to the Ag NPs nuclei seeds and Ag NPs size growth. As Mie's theory predicts only a single surface plasmon resonance (SPR) band for spherical Ag NPs, the observed two or more SPR bands are indicative of anisotropic morphology of our as-made Ag NPs (in the presence of bacterial cells) [38]. The wide band (shoulder) at 400-600 nm indicates the red-shift of spectrum due to the decrease in the inter-particle distance (formation of NPs aggregation) and/or an increase in the size of NPs. TEM image was further employed to demonstrate the formation of Ag NPs on the surface of bacteria by external mode (Figure 2b). A broader size distribution of NPs was observed in the TEM images. Figure $2 b$ shows the formation of NPs aggregate on the surface of bacteria. EDS result further demonstrates that the NPs attributed to be silver (Figure 2c).

\section{NIR-SERS discrimination of bacteria}

We then tested our modified SERS approach to characterize several common disease related bacterial species. Figures 3 and 4 show the spectral data for the bacterial species namely, Pseudomonas aeruginosa, Listeria monocytogenes and Listeria innocua and MRSA-86, MRSA-35. As can be seen in Figure 3, we were able to find the major Raman shifts for $P$. aeruginosa for positions at 893, 1,040 and $1,411 \mathrm{~cm}^{-1}$, which are attributed to be the vibrations from phosphodiester backbone, phenylalanine and COO- functional group respectively (details of assignments in Additional file 1: Table S1). It is observed that these three peaks are present in all the bacterial spectra studied in this report, though the relative intensities of the peaks vary among different bacteria. Figure $3 \mathrm{~b}$ shows the SERS spectra for two species of Listeria. The positions of the major shifts are almost identical between the two species, including three peaks mentioned above and others (863, 946, 1,134, 1,237, 1,612 and 1,651 $\left.\mathrm{cm}^{-1}\right)$. Figure $3 c$ shows the intensity ratio of significant peaks 

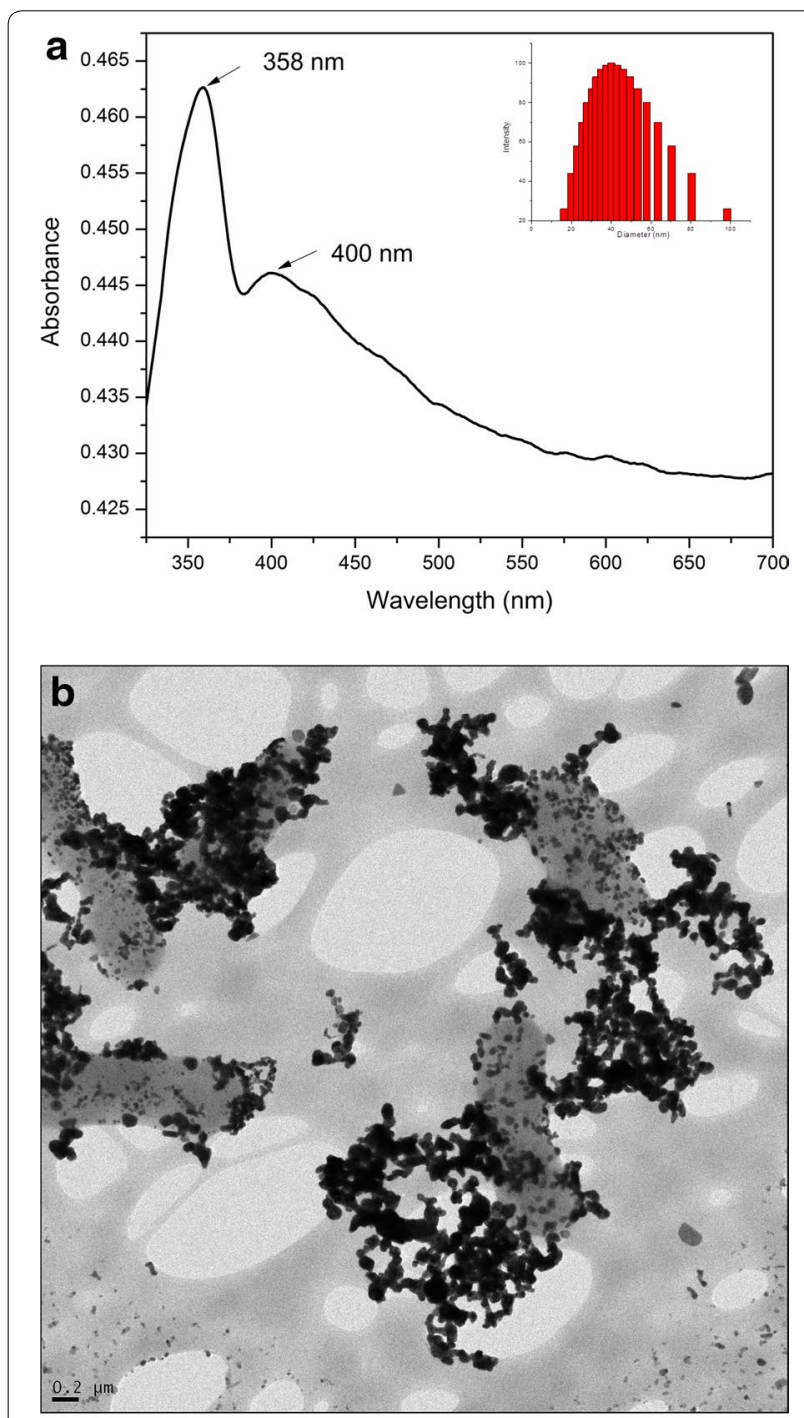

\section{C}

\section{Label: LSecs : 100}

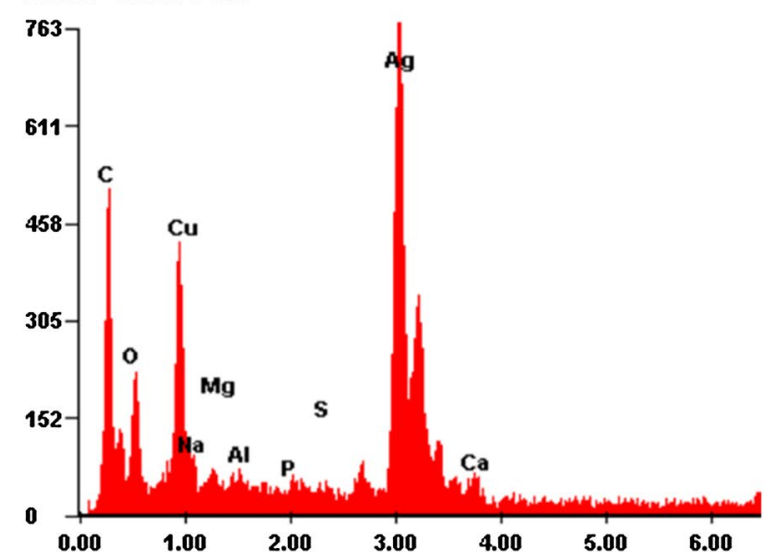

Figure $\mathbf{2}$ a UV-visible spectrum of Ag NPs prepared within bacteria mixture (external mode). $\mathbf{b}$ TEM image and $\mathbf{c}$ EDS analysis of the sample from external mode, respectively.
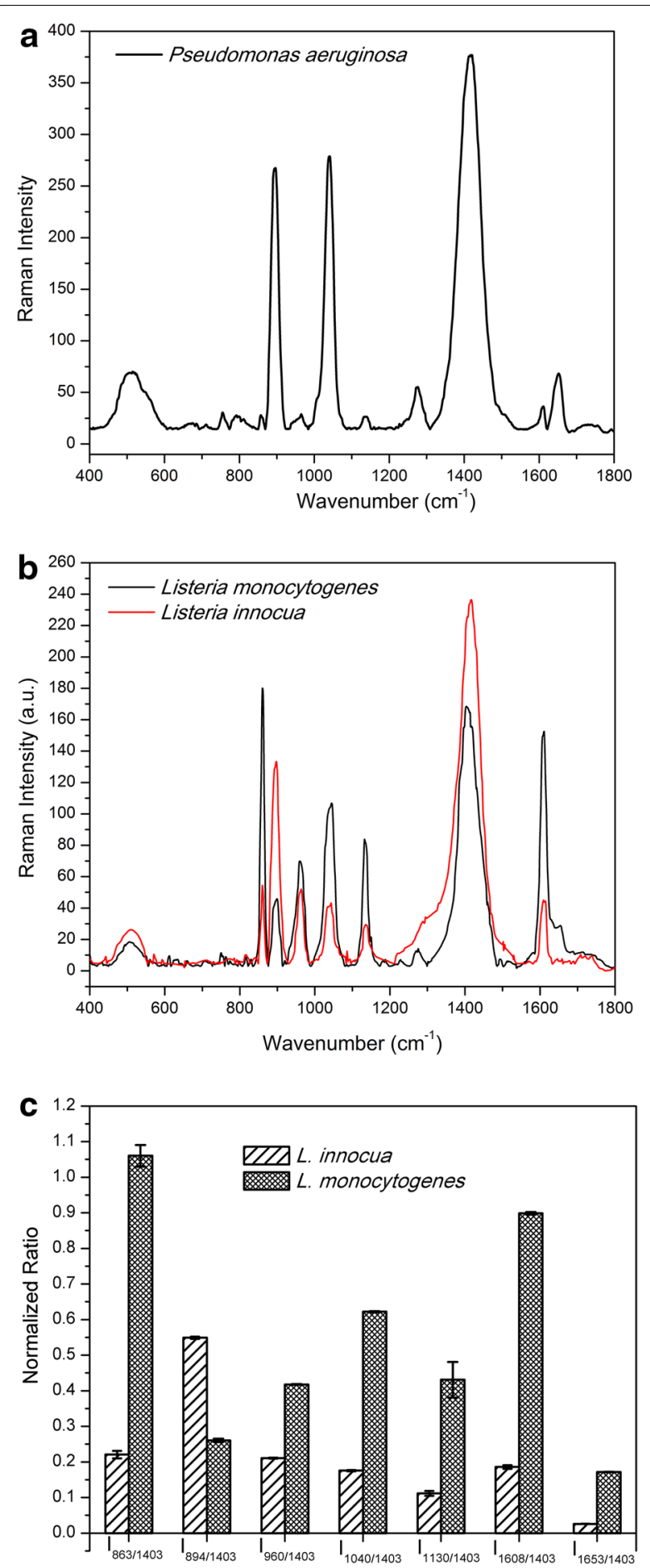

Figure 3 Averaged SERS spectra of $\mathbf{a} P$. aeruginosa and $\mathbf{b}$ two species of Listeria (L. monocytogenes and L. innocua). c Normalized intensity ratio of significant peaks from two Listeria spp. to the band at $1,040 \mathrm{~cm}^{-1}$ 
to the band at $1,040 \mathrm{~cm}^{-1}$. The band $1,040 \mathrm{~cm}^{-1}$ was selected as it has a strong intensity in all the bacterial species. The peak at $863 / 1,040 \mathrm{~cm}^{-1}$ for $L$. monocytogenes is significantly larger. Additionally, the band at $1,608 \mathrm{~cm}^{-1}$ is much stronger than the band observed for all other bacteria. In L. innocua, the largest ratio comes from the one at $894 \mathrm{~cm}^{-1}$ (Figure 3c). We were able to discriminate between the two species of Listeria using the relative ratios of these peaks. Furthermore, it could be observed that there is an obvious difference in the Raman frequency at position $1,658 \mathrm{~cm}^{-1}$ (Figure $3 \mathrm{~b}$ ), where the spectrum of $L$. monocytogenes shows a unique peak following the shoulder of the vibration band at $1,612 \mathrm{~cm}^{-1}$. Therefore, it could be concluded that we were able to efficiently and rapidly discriminate between the two Listeria species with the developed SERS method.

We further evaluated if our SERS approach could identify strains from the same bacterial species. As seen in
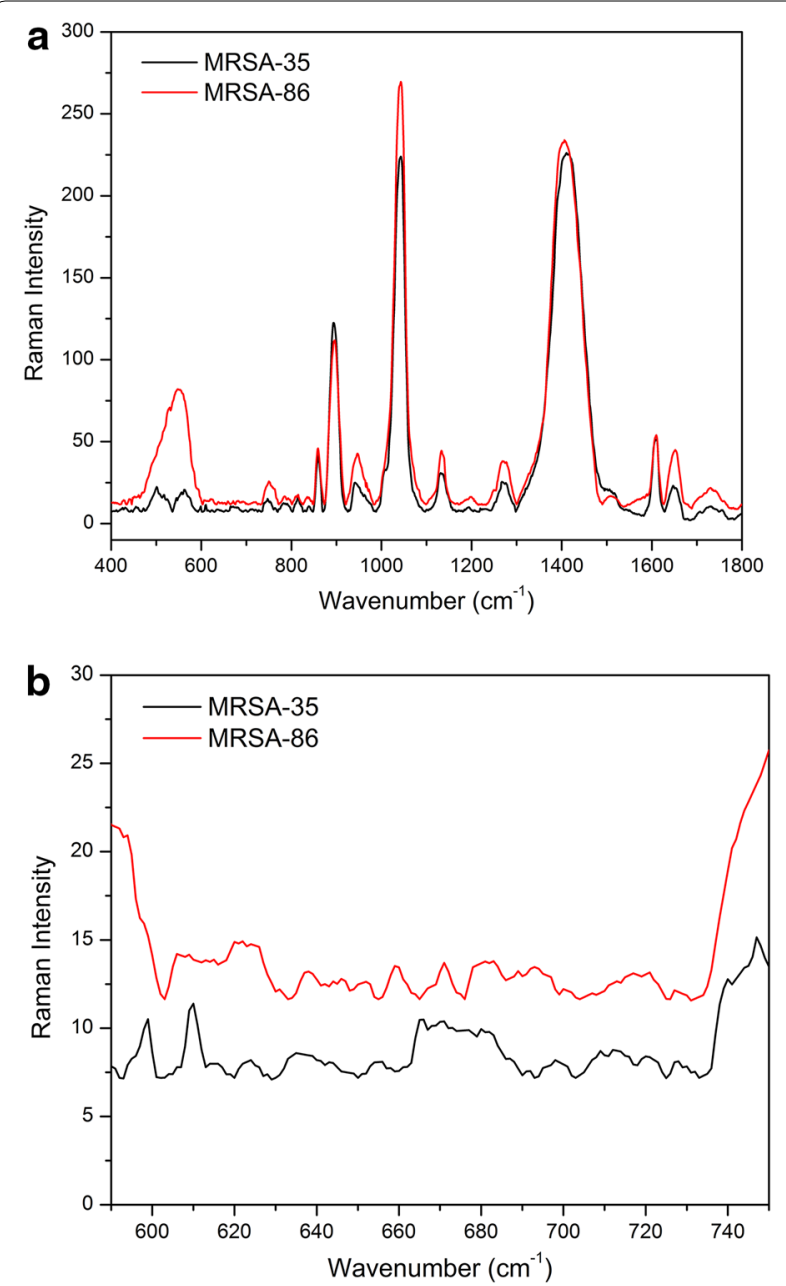

Figure 4 Averaged SERS spectra of $\mathbf{a}$ two strains of MRSA, b Zoom-in view of the spectra of two MRSA strains.
Figure 4, the spectra from two MRSA strains exhibited highest peak intensity at the position $1,040 \mathrm{~cm}^{-1}$. The two MRSA strains show almost identical Raman spectra as observed in Figure 4a. Apart from the three major peaks, there are other peaks with medium intensity, including $863,946,1,134,1,237,1,612$ and $1,651 \mathrm{~cm}^{-1}$ present in two MRSA strains. The band ascribed to be P-O-C binding of phospholipids at position 546 is present in MRSA-86. However, for MRSA-35, we found two peaks (unassigned) with medium intensity around the same location. As the differences and intensities of the bands are small, it is difficult to conclude that that they could be satisfactorily distinguish between the two different strains. The minor differences in peaks might also be due to disruption of cell wall by other factors such as mixing and centrifugation during the experiment. Albeit identical features in major peaks, we could find minor differences between the two strains in the peaks ranging from 600 to $700 \mathrm{~cm}^{-1}$. As can be seen in Figure 4b, a zoom-in view shows two small peaks (599 and $609 \mathrm{~cm}^{-1}$ ) and the appearance of a broad band around $670 \mathrm{~cm}^{-1}$ in MRSA35. Meanwhile, in MRSA-86, there are peaks of spectral data with broadband at $610 \mathrm{~cm}^{-1}$ and another new peak at $659 \mathrm{~cm}^{-1}$. We were able to discriminate the two MRSA species based on these minor spectral differences.

Clustering of the bacterial spectrum samples can be seen in Figure 5. The results from the PCA analysis shows that each group of bacterial species separate out from each other allowing for discrimination between species. However, it can be noted that L. innocua showed a degree of overlap with $P$. aeruginosa (Figure 5). This could be due to the spectral interference from pigments pyocyanin and

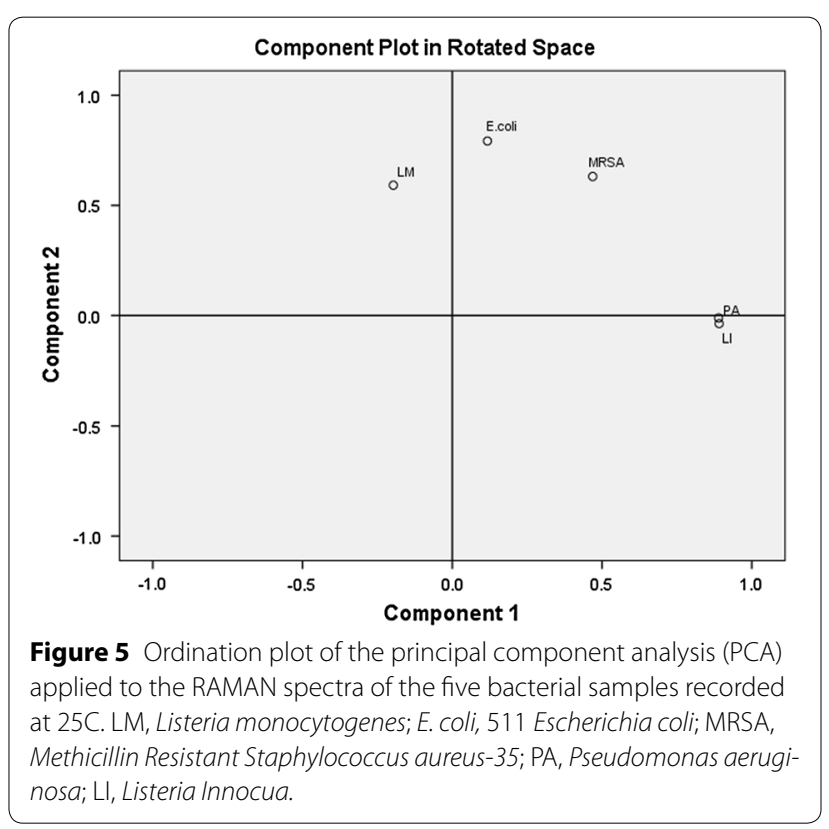


pyoverdine, which are released by the Pseudomonas species which was visually observed from the plates $[39,40]$.

For $P$. aeruginosa, biofilm embedded with carbohydrates, nuclei acids and proteins may also contribute to the spectral interference. A recent study revealed a significant increase in peak intensities attributed to carbohydrates and proteins during biofilm accumulation period [41]. It is possible that the Raman spectra of $P$. aeruginosa examined in our study are contributed by the biofilm components rather than the bacterial cell wall. As shown in Figure 3, apart from three relatively strong bands in the SERS spectrum of $P$. aeruginosa, which are attributed to nucleic acids $\left(896 \mathrm{~cm}^{-1}\right)$, carbohydrates $\left(1,040 \mathrm{~cm}^{-1}\right)$ and proteins (COO-, $\left.1,411 \mathrm{~cm}^{-1}\right)$, there are very few weaker peaks, suggesting that biofilm formation may directly contribute to the spectral interference for $P$. aeruginosa.

The results of this study provide a promising avenue for the development of a diagnostic platform for rapid discrimination, identification and classification of pathogenic microbial agents towards healthcare applications. Bacterial concentration may potentially obscure the relative peak intensity and the baseline intensity. However, modifying the surface of the substrates, and using microfluidics to avoid spectral interference in RAMAN spectra from mixed bacterial samples using the proposed in situ approach can achieve a uniform concentration of bacteria. The result of this study provides promising potential to develop a SERS based platform for field deployable, handheld point-of-care detection tool for rapid detection of pathogenic bacterial microorganisms including Vibrio spp. To achieve the above target, further miniaturization of the RAMAN spectrometer is a prerequisite. Challenges associated with the integration of the RAMAN spectrometer and the microfluidic device platform, and field based sample pre-processing protocols of the food matrix have to be considered towards the successful deployment of the NIR-SERS technique to discriminate and detect the foodborne pathogens.

\section{NIR-SERS detection of bacterium Listeria innocua}

To investigate if the current assay mode could be used to determine the concentration of bacteria from SERS data, we collected the SERS spectra of L. innocua at different concentrations (from $10^{3} \mathrm{CFU} / \mathrm{mL}$ to $10^{5} \mathrm{CFU} / \mathrm{mL}$ ) using Nanopure $^{\mathrm{TM}}$ water as a control (Figure 6). This concentration window is considered to be a lethal dose of Listeria. spp. [42]. As discussed above, the peaks at $\Delta \mathrm{v}=860,894$ and $960 \mathrm{~cm}^{-1}$ were significantly stronger for Listeria. $s p$. Specifically, the intensity of the peak at $960 \mathrm{~cm}^{-1}$ increased as the bacterial concentration was increased. In addition, the peak corresponding to $\mathrm{N}-\mathrm{C}$ stretching has been previously reported to be SERS peak for Listeria $s p$. by other groups [43]. Hence we believe that the peak at $\Delta \mathrm{v}=960 \mathrm{~cm}^{-1}$ could be used as signature peak used to
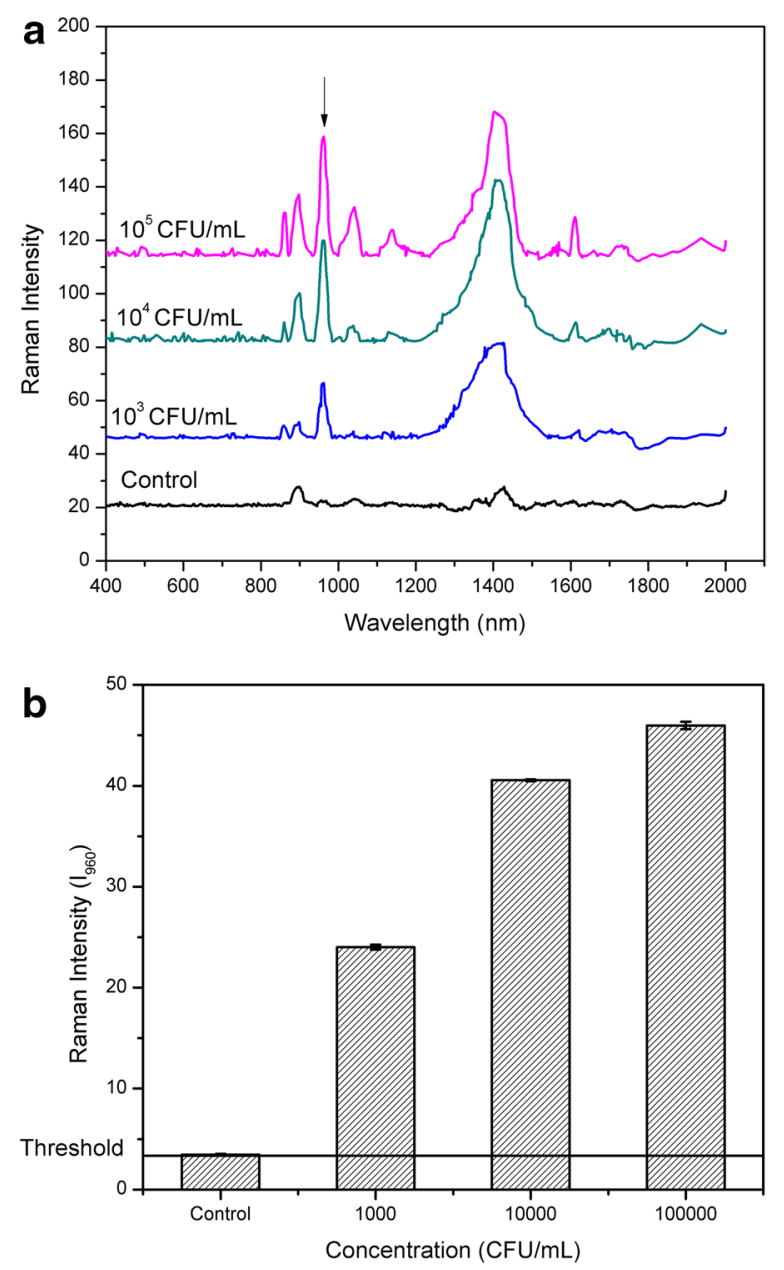

Figure 6 a SERS spectra of L. innocua at different concentrations (from $103 \mathrm{CFU} / \mathrm{mL}$ to $105515 \mathrm{CFU} / \mathrm{mL}$ ) and Nanopure ${ }^{\mathrm{TM}}$ water as a control. b Plot of the SERS peaks intensity at $\Delta v=960 \mathrm{~cm}^{-1}(1960)$ against the bacterial concentration of L. innocua.

estimate the concentration of Listeria sp. (L. innocua was used in the present study). In order to establish the limit of detection (LOD) for L. innocua samples, we plotted the SERS peak intensity at $\Delta \mathrm{v}=960 \mathrm{~cm}^{-1}$ (I960) with respect to the bacterial concentration (Figure 6b). At least nine spectra were measured for each concentration and analyzed by peak fitting. The mean and standard deviation of peak intensities are shown in Figure $6 \mathrm{~b}$. The value of average plus three times the standard deviation of the sterile DI water was set as the limit to distinguish a positive detection from negative detection. The lowest concentration of pure L. innocua detected by our assay was $10^{3} \mathrm{CFU} / \mathrm{mL}$.

\section{Conclusions}

We presented a label-free NIR-SERS approach for discrimination of bacteria in water through synthesis of $\mathrm{Ag}$ 
NPs within bacterial culture. We found that pre-treatment of Triton X-100 resulted in new features in SERS spectra, attributed to the inner components of the bacterial cell wall. Successful discrimination of common disease related bacteria including $E$. coli, P. aeruginosa, Listeria and MRSA were achieved. Furthermore, we were also able to identify two Listeria species (L. monocytogenes and L. іпnосиа). Using the label-free NIR-SERS approach, we could also differentiate between two strains of MRSA isolated from clinical samples. The assay could be completed in less than $5 \mathrm{~min}$. The assay requires very low volume of sample, which is a unique advantage. The developed assay can be used as a promising tool for selective discrimination of bacteria and will open new avenues for the development of point-of-care diagnostic devices with biomedical and food safety applications.

\section{Methods}

\section{Chemicals and materials}

Silver nitrate $\left.(\mathrm{Ag} \mathrm{NO})_{3}\right)$, sodium borohydride $\left(\mathrm{NaBH}_{4}\right)$, Triton X-100 and phosphate buffered saline (PBS) tablets were purchased from Sigma-Aldrich (Sigma-Aldrich, Oakville, Canada). Only Milli-Q water $(18.2 \mathrm{~m} \Omega \mathrm{cm})$ was used in this study. Bacterium E. coli (ATCC 25992) was purchased from ATCC. All other bacterial strains, including L. innocua, L. monocytogenes 1892, two strains of Methicillin-resistant S. aureus (MRSA) (USA100 defined as MRSA-35 and USA 300 defined as MRSA-86), and $P$. aeruginosa BK-76 used throughout this study, were isolated from clinical samples and received as gifts from the Canadian Research Institute for Food Safety (CRIFS) and the Ontario Veterinary College Hospital of the University of Guelph.

\section{Bacterial preparation}

Bacterial cell suspensions were prepared from overnight cultures, grown overnight in $5 \mathrm{~mL}$ culture medium at $37^{\circ} \mathrm{C}$ and $150 \mathrm{rpm}$. For MRSA, the culture medium is brain heart infusion (BHI) broth (Oxoid Canada, Nepean, ON, Canada). For the other bacterial species, the culture medium was tryptone soy broth (TSB, Oxoid Canada, Nepean, ON, Canada). The bacterial cultures were then harvested and washed twice in water by centrifugation at $4,500 \mathrm{~g}$ for $10 \mathrm{~min}$ at $4^{\circ} \mathrm{C}$. Afterwards, the bacterial cells were resuspended in water for further analysis.

\section{SERS measurement}

For SERS internal mode, harvested bacterial cells were resuspended in $\mathrm{AgNO}_{3}$ solution (1 M) and incubated for $5 \mathrm{~min}$. The cells were then collected and washed twice in water by centrifugation at $4,500 \mathrm{~g}$ for $10 \mathrm{~min}$ at $4{ }^{\circ} \mathrm{C}$. Afterwards, the cells were resuspended in $\mathrm{NaBH}_{4}$ solution $(0.5 \mathrm{M})$ for further analysis. For SERS external mode, harvested bacterial cells were first resuspended in $\mathrm{NaBH}_{4}$ solution and incubated for $5 \mathrm{~min}$. The cells were then collected by centrifugation and resuspended in $\mathrm{AgNO}_{3}$ solution for further analysis. In a typical experiment, the bacterial cells were treated with $0.1 \%$ Triton X-100 (v/v) for $5 \mathrm{~min}$, prior to the assay. Then, $10 \mu \mathrm{L}$ of treated bacterial suspension $\left(\sim 1 \times 10^{6} \mathrm{CFU} / \mathrm{mL}\right)$ was mixed with $10 \mu \mathrm{L}$ of $\mathrm{NaBH}_{4}(0.5 \mathrm{M})$. The mixture was then incubated for 3-5 min. Subsequently, $800 \mu \mathrm{L}$ of $\mathrm{AgNO}_{3}(1 \mathrm{M})$ was pipetted into the mixture followed by vortexing.

Raman analysis was conducted by addition of $5 \mu \mathrm{L}$ of the bacterial suspensions obtained from above modes onto the surface of glass cover slips $(0.13 \mathrm{~mm}$ thickness, $15 \mathrm{~mm}$ diameter, Ted Pella Inc., Redding, CA, USA). SERS spectra were recorded on a benchtop Raman spectrometer (Sierra Snowy Range 785 series, Laramie, WY, USA) under excitation wavelength of $785 \mathrm{~nm}$. The exposure time was $1 \mathrm{~s}$ and the number of accumulations for each measurement was 10 . The spectral data were acquired over a Stokes Raman shift of $400-2,000 \mathrm{~cm}^{-1}$. For each study, three biological replicates were analyzed. To validate the results of the strain level discrimination, additional replicate was also analyzed.

\section{Statistical and PCA analysis}

Statistical analysis was conducted using IBM SPSS Statistics 22 software. Principal component analysis was conducted using Matlab 2000b (The Mathworks, Inc., Natick, MA, USA) using the PLS toolbox (Eigenvector Research Inc., Wenatchee, WA, USA). Principal component analysis (PCA) was used to reduce the dimensionality of the multivariate data, and transform and identify the original set of variables into uncorrelated new variables through principal components. Upon plotting the principal components, the data from similar spectra were grouped as per the principal component scores. A total of 18 biological replicates for each bacterial species were used in acquiring the Raman spectra. Data analyses were performed on all the acquired Raman spectra for individual bacterial species. The SERS spectra were processed by taking the first derivative of the each spectrum and then were normalized to the unit vector length, followed by mean centering and auto-scaling prior to analysis of the data.

\section{Characterization}

Transmission electron microscopy (TEM) images were acquired by Philips CM-10 equipment coupled with energy dispersive spectroscopy (EDS) operated at $120 \mathrm{kV}$. The UV-Vis absorption spectra were recorded by UV-3600 spectrophotometer (Shimadzu, Japan). The size distribution of Ag NPs in water was measured by dynamic light scattering with Zetasizer Nano ZS 
(Malvern Instrument Ltd. Worcestershire, UK), equipped with a glass cell.

\section{Additional file}

Additional file 1: Table S1. Tentative assignments ${ }^{a}$, and strength $^{b}$ of peaks from SERS spectra of 5 bacteria $[16,26,41-43]$.

\section{Authors' contribution}

SN conceptualized the idea for this study. SN and LC designed the study. NM, LD and LC conducted the experiments. SN and LC analyzed the data. LC wrote the manuscript with SN. All authors read and approved the final manuscript.

\section{Acknowledgements}

The authors sincerely thank the Natural Sciences and Engineering Research Council of Canada, Ontario Ministry of Research and Innovation, and the Dairy Farmers of Ontario for funding this study.

\section{Compliance with ethical guidelines}

Competing interests

The authors declare that they have no competing interests.

Received: 31 March 2015 Accepted: 17 June 2015

Published online: 25 June 2015

\section{References}

1. Lazcka O, Campo FJD, Muñoz FX (2007) Pathogen detection: A perspective of traditional methods and biosensors. Biosens Bioelectron 22:1205-1217

2. Walker HK, Hall WD, Hurst JW (1990) Clinical methods: the history, physical, and laboratory examinations. Butterworths, UK

3. Andersson DI, Hughes D (2010) Antibiotic resistance and its cost: is it possible to reverse resistance? Nat Rev Micro 8:260-271

4. Swaminathan B, Feng P (1994) Rapid detection of food-borne pathogenic bacteria. Annu Rev Microbiol 48:401-426

5. Wu X, Xu C, Tripp RA, Huang Y-W, Zhao Y (2013) Detection and differentiation of foodborne pathogenic bacteria in mung bean sprouts using field deployable label-free SERS devices. Analyst 138:3005-3012

6. Driskell JD, Kwarta KM, Lipert RJ, Porter MD, Neill JD, Ridpath JF (2005) Low-level detection of viral pathogens by a surface-enhanced Raman scattering based immunoassay. Anal Chem 77:6147-6154

7. Gilmartin N, O'Kennedy R (2012) Nanobiotechnologies for the detection and reduction of pathogens. Enzyme Microb Technol 50:87-95

8. Drake P, Jiang P-S, Chang H-W, Su S-C, Tanha J, Tay L-L et al (2013) Raman based detection of Staphylococcus aureus utilizing single domain antibody coated nanoparticle labels and magnetic trapping. Anal Methods 5:4152-4158

9. Cheng IF, Chang H-C, Chen T-Y, Hu C, Yang F-L (2013) Rapid ( $<5$ min) identification of pathogen in human blood by electrokinetic concentration and surface-enhanced Raman spectroscopy. Sci Rep 3:1-8

10. Tu Q, Chang C (2012) Diagnostic applications of Raman spectroscopy. Nanomed Nanotechnol Biol Med 8:545-558

11. Efrima S, Zeiri L (2009) Understanding SERS of bacteria. J Raman Spectrosc 40:277-288

12. Vandenabeele P (2010) Raman spectroscopy. Anal Bioanal Chem 397:2629-2630

13. Campion A, Kambhampati P (1998) Surface-enhanced Raman scattering Chem Soc Rev 27:241-250

14. Jarvis RM, Goodacre R (2004) Discrimination of bacteria using surfaceenhanced Raman spectroscopy. Anal Chem 76:40-47

15. Naja G, Bouvrette P, Hrapovic S, Luong JHT (2007) Raman-based detection of bacteria using silver nanoparticles conjugated with antibodies. Analyst 132:679-686
16. Premasiri WR, Moir DT, Klempner MS, Krieger N, Jones G, Ziegler LD (2004) Characterization of the Surface Enhanced Raman Scattering (SERS) of Bacteria. J Phys Chem B 109:312-320

17. Xie Y, Xu L, Wang Y, Shao J, Wang L, Wang H et al (2013) Label-free detection of the foodborne pathogens of Enterobacteriaceae by surfaceenhanced Raman spectroscopy. Anal Methods 5:946-952

18. Zeiri L, Bronk BV, Shabtai Y, Czégé J, Efrima S (2002) Silver metal induced surface enhanced Raman of bacteria. Colloids Surf A 208:357-362

19. Park B, Seo Y, Yoon S-C, Hinton A Jr, Windham WR, Lawrence KC (2015) Hyperspectral microscope imaging methods to classify gram-positive and gram-negative foodborne pathogenic bacteria. Trans ASABE 58:5-16

20. Zhang L, Xu J, Mi L, Gong H, Jiang S, Yu Q (2012) Multifunctional magnetic-plasmonic nanoparticles for fast concentration and sensitive detection of bacteria using SERS. Biosens Bioelectron 31:130-136

21. Zhou H, Yang D, Ivleva NP, Mircescu NE, Niessner R, Haisch C (2014) SERS detection of bacteria in water by in situ coating with Ag nanoparticles. Anal Chem 86:1525-1533

22. Zhang X, Young MA, Lyandres O, Van Duyne RP (2005) Rapid detection of an anthrax biomarker by surface-enhanced Raman spectroscopy. J Am Chem Soc 127:4484-4489

23. Liu T-T, Lin Y-H, Hung C-S, Liu T-J, Chen Y, Huang Y-C et al (2009) a high speed detection platform based on surface-enhanced Raman scattering for monitoring antibiotic-induced chemical changes in bacteria cell wall. PLoS One 4:e5470

24. Lin Y, Hamme li AT (2014) Targeted highly sensitive detection/eradication of multi-drug resistant Salmonella DT104 through gold nanoparticleSWCNT bioconjugated nanohybrids. Analyst 139:3702-3705

25. Zeiri L, Bronk BV, Shabtai Y, Eichler J, Efrima S (2004) Surface-enhanced Raman spectroscopy as a tool for probing specific biochemical components in bacteria. Appl Spectrosc 58:33-40

26. Smith-Palmer T, Douglas C, Fredericks P (2010) Rationalizing the SER spectra of bacteria. Vib Spectrosc 53:103-106

27. Sengupta A, Laucks ML, Davis EJ (2005) Surface-enhanced Raman spectroscopy of bacteria and pollen. Appl Spectrosc 59:1016-1023

28. Sung K, Khan SA, Nawaz MS, Khan AA (2003) A simple and efficient Triton X-100 boiling and chloroform extraction method of RNA isolation from Gram-positive and Gram-negative bacteria. FEMS Microbiol Lett 229:97-101

29. Jalalirad R (2013) Selective and efficient extraction of recombinant proteins from the periplasm of Escherichia coli using low concentrations of chemicals. J Ind Microbiol Biotechnol 40:1117-1129

30. Ma X, Su E, Deng S, Xie Y, Wei D (2014) An efficient method for recovering recombinant cephalosporin c deacetylase from the cytoplasm of $E$. coli cells. Chem Biochem Eng Q 28:349-355

31. Prucek R, Ranc V, Kvitek L, Panacek A, Zboril R, Kolar M (2012) Reproducible discrimination between gram-positive and gram-negative bacteria using surface enhanced Raman spectroscopy with infrared excitation. Analyst 137:2866-2870

32. Wang M, Jing N, Chou IH, Cote GL, Kameoka J (2007) An optofluidic device for surface enhanced Raman spectroscopy. Lab Chip 7:630-632

33. Huang WE, Li M, Jarvis RM, Goodacre R, Banwart SA (2010) Chapter 5Shining light on the microbial world: the application of raman microspectroscopy In: Advances in Applied Microbiology, vol 70. Academic Press, Burlington, pp 153-186

34. Brauchle E, Schenke-Layland K (2013) Raman spectroscopy in biomedicine-non-invasive in vitro analysis of cells and extracellular matrix components in tissues. Biotechnol J 8:288-297

35. Schuck S, Honsho M, Ekroos K, Shevchenko A, Simons K (2003) Resistance of cell membranes to different detergents. Proc Natl Acad Sci USA 100:5795-5800

36. Helander IM, Nurmiaho-Lassila EL, Ahvenainen R, Rhoades J, Roller S (2001) Chitosan disrupts the barrier properties of the outer membrane of gram-negative bacteria. Int J Food Microbiol 71:235-244

37. Chauhan AK, Kang SC (2014) Thymol disrupts the membrane integrity of Salmonella ser. typhimurium in vitro and recovers infected macrophages from oxidative stress in an ex vivo model. Res Microbiol 165:559-565

38. Shen J, Shi M, Ma H, Yan B, Li N, Hu Y et al (2010) Synthesis of hydrophilic and organophilic chemically modified graphene oxide sheets. J Colloid Interface Sci 352:366-370 
39. Wu X, Chen J, Li X, Zhao Y, Zughaier SM (2014) Culture-free diagnostics of Pseudomonas aeruginosa infection by silver nanorod array based SERS from clinical sputum samples. Nanomedicine 10:1863-1870

40. Wu X, Chen J, Zhao Y, Zughaier SM (2014) Rapid detection of Pseudomonas aeruginosa biomarkers in biological fluids using surfaceenhanced Raman scattering. In: 91070A-91070A-91010

41. Feng J, de la Fuente-Nunez C, Trimble MJ, Xu J, Hancock RE, Lu X (2015) An in situ Raman spectroscopy-based microfluidic "lab-on-a-chip" platform for non-destructive and continuous characterization of Pseudomonas aeruginosa biofilms. Chem Commun (Camb) 51:8966-8969
42. Roche SM, Gracieux P, Albert I, Gouali M, Jacquet C, Martin PM et al (2003) Experimental validation of low virulence in field strains of Listeria monocytogenes. Infect Immun 71:3429-3436

43. Luo BS, Lin MIN (2008) A portable Raman system for the identification of foodborne pathogenic bacteria. J Rapid Methods Autom Microbiol $16: 238-255$

\section{Submit your next manuscript to BioMed Central} and take full advantage of:

- Convenient online submission

- Thorough peer review

- No space constraints or color figure charges

- Immediate publication on acceptance

- Inclusion in PubMed, CAS, Scopus and Google Scholar

- Research which is freely available for redistribution

Submit your manuscript at

www.biomedcentral.com/submit

C Biomed Central 